\title{
Requirement of Innate Immunity in Tumor-Bearing Mice Cured by Adoptive Immunotherapy Using Tumor-Draining Lymph Nodes
}

\author{
John Ammori, Khaled Hamzeh, Hallie Graor, and Julian Kim \\ Division of Surgical Oncology, Department of Surgery, University Hospitals Case Medical Center and \\ Case Comprehensive Cancer Center, Cleveland, OH 44106, USA
}

Correspondence should be addressed to John Ammori; john.ammori@uhhospitals.org

Received 30 December 2014; Revised 25 March 2015; Accepted 26 March 2015

Academic Editor: David E. Gilham

Copyright (C) 2015 John Ammori et al. This is an open access article distributed under the Creative Commons Attribution License, which permits unrestricted use, distribution, and reproduction in any medium, provided the original work is properly cited.

\begin{abstract}
Background. The purpose of this study was to determine the cellular effectors of both the adoptively transferred cells and the tumor-bearing host that participate in the antitumor response to adoptive immunotherapy using culture-activated tumor-draining lymph nodes (TDLNs). Methods. TDLNs harvested from mice with 4 T1 carcinoma cells were fractionated to derive the L-selectin ${ }^{\text {low }}$ subpopulation and activated ex vivo prior to in vitro cytokine release assays and adoptive transfer into BALB/c mice bearing 3-day established subcutaneous tumors. Tumor-bearing recipients were SCID (lacking T, B, and NK cells), Rag2 deficient (lacking T and B cells), and wild-type BALB/c mice. Results. Culture-activated L-selectin ${ }^{\text {low }} 4 \mathrm{~T} 1 \mathrm{TDLN}$ from BALB/c mice secreted significant levels of interferon-gamma in response to $4 \mathrm{~T} 1$ but not control tumor cells in vitro. CD4 cells within the adoptively transferred effector cell population contributed significantly to the antitumor effect in vivo. Culture-activated L-selectin ${ }^{\text {low }}$ TDLNs from BALB/c wild-type mice were able to cure Rag2 deficient but not SCID mice bearing $4 \mathrm{~T} 1$ subcutaneous tumors, suggesting a requirement of NK cells within the innate immune system of the tumor-bearing host during the antitumor response. Conclusions. These results identify the cellular effectors involved in tumor regression following adoptive transfer and demonstrate the requirement for intact innate immunity within the tumor-bearing host.
\end{abstract}

\section{Introduction}

Adoptive transfer of immune cells into a cancer-bearing host has been shown to be efficacious both in animal models and in human trials. Several approaches have been used, such as the use of tumor-infiltrating lymphocytes, dendritic cell vaccines, lymphokine-activated killer cells, vaccine-primed lymph nodes, chimeric antigen receptor-modified $\mathrm{T}$ cells, and tumor-draining lymph node (TDLN) cells [1-13]. Several groups have explored adoptive immunotherapy (AIT) using TDLN, which has shown significant therapeutic activity against a variety of murine tumors [4, 6, 8, 12-19]. Lymph nodes (LN) draining progressively growing subcutaneous tumors contain antigen-specific preeffector $\mathrm{T}$ cells which have been sensitized to tumor cells but are not fully functional effector T cells. Following ex vivo activation with anti-CD3 and culture with interleukin-2 (IL-2), these preeffector cells acquire tumor-specific effector function against established tumor in vivo [18]. Despite the polyclonal nature of the cell culture with anti-CD3 and IL-2, the resultant T cells mediate in vivo antitumor effect only against the tumor with which they were stimulated in vivo [12]. Though demonstrating in vivo therapeutic effect, these cells do not exhibit cytotoxic activity against tumor targets in vitro in some experimental models while they do in others $[12,20]$. Activated TDLNs secrete interferon- $\gamma$ (IFN- $\gamma$ ) in response to exposure to tumor cells in vitro $[5,15,20-22]$.

To optimize therapeutic efficacy, the number and type of cells transferred are important. Fresh TDLN cells transferred to a cancer bearing animal result in no tumor response. $E x$ vivo expansion with anti-CD3 and IL-2 not only expands the number of cells by several folds but also activates the cells for therapeutic effect. In addition, T cells with low expression of the $\mathrm{T}$ cell homing receptor $\mathrm{L}$-selectin (L-selectin ${ }^{\text {low }}$ ) 


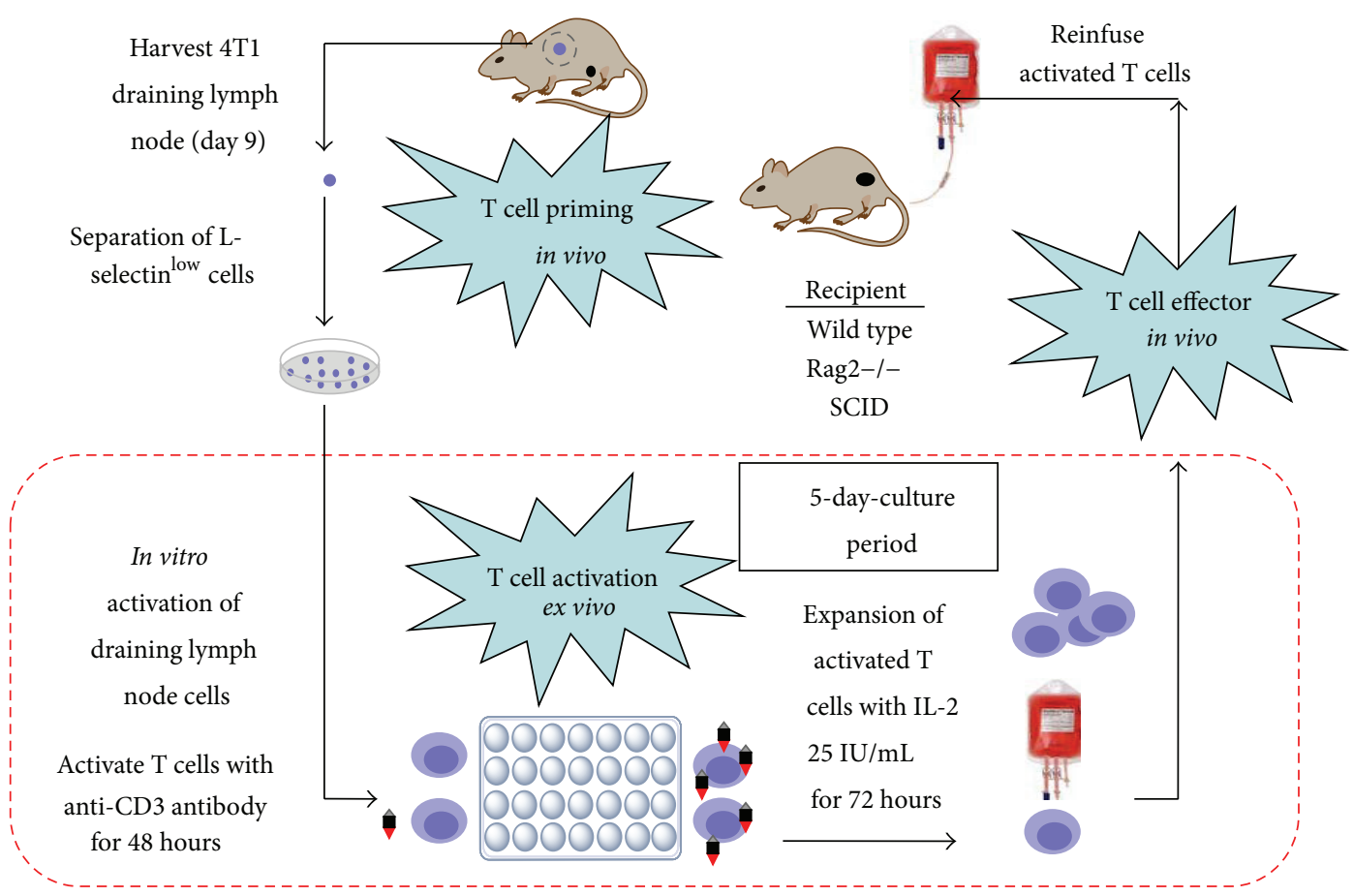

FIgURE 1: Tumor vaccination, T cell activation, and adoptive transfer.

represent a group of potent tumor reactive T cells from within the total TDLN cell population [21, 23-25]. Transferred Lselectin $^{\text {low }}$ cells isolated from TDLN had a 30-fold greater therapeutic efficacy than unfractionated TDLN cells [23]. Cytokine secretion is induced by exposure of activated T cells to tumor cells in vitro $[23,24]$. Transfer of only L-selectin ${ }^{\text {high }}$ cells had no therapeutic effect $[23,24]$. L-selectin ${ }^{\text {high }}$ cells have been shown to act as suppressor T cells that can prevent L-selectin $^{\text {low }} \mathrm{T}$ cell antitumor activity [26]. The experiments in this study utilize L-selectin ${ }^{\text {low }}$ T cells from TDLN.

Freshly harvested lymph nodes contain an array of immune cell types. After expansion and activation with antiCD3 and IL-2, the cell population is enriched with T cells. During in vivo tumor growth, sensitization of CD8 T cells in the TDLN occurs independently from sensitization of CD4 $\mathrm{T}$ cells [13]. During in vitro expansion and activation with anti-CD3 and IL-2, CD8 cells require the helper function of CD4 cells [13]. In some experimental models, transfer of either CD4 or CD8 cells activated TDLN cells induced in vivo tumor regression, while in other models CD4 alone or CD8 alone was therapeutically ineffective $[15,21,23]$. The role of the host immune system in adoptive $\mathrm{T}$ cell therapy is not entirely clear. Regulatory $\mathrm{T}$ cells suppress tumor reactive $\mathrm{T}$ cells, and lymphodepletion with chemotherapy has been used as an approach to enhance adoptive T cell therapy [27].

The purpose of this study was to determine the cellular effectors that play a central role in the antitumor efficacy of adoptive immunotherapy using TDLN in an animal model. In this report, we demonstrate that treatment with L-selectin $^{\text {low }} \mathrm{T}$ cells from TDLN draining 4T1 mammary tumors cause tumor regression. The CD4 cells demonstrate more therapeutic activity than the CD8 cells. Natural killer (NK) cells and/or other components of the innate immune system in the tumor-bearing host are necessary for antitumor effect of the transferred TDLN cells.

\section{Materials and Methods}

2.1. Adoptive Immunotherapy Protocol. The 4T1 is a 6thioguanine-resistant cell line that was selected from a tumor cell line derived from a single spontaneously arising mammary tumor in a BALB/c3H mouse. All animal studies were approved by the Institutional Animal Care and Use Committee. Eight 12-week-old female BALB/c mice were inoculated subcutaneously with $1 \times 10^{6} 4 \mathrm{~T} 1$ mammary tumor cells in the bilateral flanks. After 9 days of tumor growth, draining inguinal lymph nodes were surgically obtained and single cells were prepared and activated in Complete Media on 24-well plates (Costar, Cambridge, MA) with immobilized anti-CD3 monoclonal antibody (clone 145-2C11) at a density of $4 \times 10^{6}$ cells $/ 2 \mathrm{~mL} /$ well for 48 hours. Following activation, cells were harvested and expanded with $25 \mathrm{U} / \mathrm{mL}$ IL-2 for 72 hours. Activated T cells were resuspended in Hank's Balanced Salt Solution (HBSS) and adoptively transferred in $1 \mathrm{~mL}$ intravenously via the tail vein to mice bearing 3-day established 4T1 subcutaneous tumors. Figure 1 demonstrates this protocol.

2.2. Immunomagnetic Selection of TDLN Subsets. Freshly harvested 4T1 TDLNs were subjected to immunodepletion using immunomagnetic beads and columns (Miltenyi Biotec). CD62L (L-selectin) microbeads were used to derive the L-selectin ${ }^{\text {low }}$ prior to anti-CD3/IL-2 culture activation. 
TABLE 1: FACS analysis of baseline 4T1 TDLNs and after culture activation of the L-selectin ${ }^{\text {low }}$ subpopulation.

\begin{tabular}{|c|c|c|c|c|c|c|c|}
\hline & $\begin{array}{c}\text { CD4 } \\
(\%(\mathrm{SD}))\end{array}$ & $\begin{array}{c}\text { CD8 } \\
(\%(\mathrm{SD}))\end{array}$ & $\begin{array}{c}\text { THY1.2 } \\
(\%(\mathrm{SD}))\end{array}$ & $\begin{array}{c}\text { L-sel } \\
(\%(\mathrm{SD}))\end{array}$ & $\begin{array}{c}\text { CD11b } \\
(\%(\mathrm{SD}))\end{array}$ & $\begin{array}{c}\text { CD11c } \\
(\%(\mathrm{SD}))\end{array}$ & $\begin{array}{c}\text { B220 } \\
(\%(S D))\end{array}$ \\
\hline \multirow{2}{*}{ Day 0: all cells } & 36.5 & 19.5 & 56.4 & 29.7 & 3.6 & 1.2 & 42.6 \\
\hline & $(7.0)$ & $(3.7)$ & $(4.5)$ & $(11.6)$ & $(0.9)$ & $(1.1)$ & $(1.1)$ \\
\hline \multirow{2}{*}{ Day 0: CD62L-low } & 27.74 & 6.0 & 35.6 & 1.4 & 6.7 & 3.5 & 55.3 \\
\hline & (9.5) & $(2.2)$ & (9.1) & $(0.6)$ & (2.1) & (3.2) & $(16.4)$ \\
\hline \multirow{2}{*}{ Day 0: CD62L-high } & 46.3 & 24.1 & 66.7 & 25.6 & 1.73 & 2.12 & 39.0 \\
\hline & (6.3) & $(4.8)$ & (9.5) & (9.9) & (1.3) & (3.7) & (9.3) \\
\hline \multirow{2}{*}{ Day 5: CD62L-low } & 33.3 & 20.9 & 59.6 & 1.6 & 1.6 & 0.9 & 46.8 \\
\hline & $(4.4)$ & $(8.5)$ & $(6.8)$ & $(0.8)$ & $(1.1)$ & $(0.2)$ & $(13.4)$ \\
\hline
\end{tabular}

4T1 TDLNs contain approximately $30 \%$ of cells that demonstrate downregulation of CD62L suggestive of antigen-priming in vivo. The L-selectin ${ }^{\text {low }}$ subpopulation contains higher proportions of CD4 prior to culture activation and consists predominantly of Thyl.2+ lymphocytes after ex vivo expansion. Each experiment was performed 5 times.

A second round of immunoselection was performed using CD4 and CD8 microbeads in select experiments.

\subsection{Tumor-Bearing Recipient Mice. Activated 4T1 TDLNs} were adoptively transferred into 3-day established tumorbearing recipient $\mathrm{BALB} / \mathrm{c}$ mice. The recipient mice included $\mathrm{BALB} / \mathrm{c}$ wild-type mice, BALB/c SCID (lacking $\mathrm{T}$ and $\mathrm{B}$ lymphocytes as well as NK cells), and BALB/c Rag2 deficient mice (lacking functional $\mathrm{T}$ and $\mathrm{B}$ lymphocytes). All mice were purchased from Jackson Laboratories, Bar Harbor, ME. Mice were followed and tumor size was assessed.

2.4. Tumor-Specific Activated T Cell Cytokine Release as Measured by ELISA. Subcutaneous tumors were established in $\mathrm{BALB} / \mathrm{c}$ mice using $4 \mathrm{~T} 1$ cells as well as the murine renal cancer cell line Renca. Activated T cells were cocultured with irradiated 4T1 or Renca cells from freshly harvested subcutaneous tumors at an effector $\mathrm{T}$ cell to tumor target $(\mathrm{E}: \mathrm{T})$ ratio of $2: 1$ in 24 well plates. Supernatants from activated $\mathrm{T}$ cell cultures were analyzed for interferon- (IFN-) $\gamma$ using ELISA (R\&D Systems). IFN $-\gamma$ release was measured and reported as $\mathrm{pg} / \mathrm{mL} / 10^{6} \mathrm{~T}$ cells $/ 24 \mathrm{hrs}$.

\section{Results}

3.1. Isolation of L-Selectin ${ }^{\text {low }} \mathrm{T}$ cells. It is known that naive $\mathrm{T}$ cells express high levels of CD62L (L-selectin ${ }^{\text {high }}$ ). L-selectin expression is lost during the effector phase and activated $\mathrm{T}$ cells are $\mathrm{L}$-selectin ${ }^{\text {low }}$. In order to characterize the T cell population obtained from TDLN, the following experiments were performed. TDLNs were harvested from the inguinal region of BALB/c mice inoculated with $4 \mathrm{~T} 1$ mammary cancer cell line. The cell population was characterized prior to culture activation. Approximately $30 \%$ of the TDLN cell population prior to culture activation was L-selectin ${ }^{\text {low }}$, suggesting antigen-priming of $\mathrm{T}$ cells within TDLN in vivo (Table 1). Both the L-selectin ${ }^{\text {low }}$ and the L-selectin ${ }^{\text {high }}$ populations consisted of a mix of CD4 and CD8 T cells as well as B lymphocytes as indicated by the B220 antigen. After 5-day culture activation of the L-selectin ${ }^{\text {low }}$ cell population, the final culture consists predominantly of a mixture of CD4 and CD8 cells at a $3: 2$ ratio. In addition, approximately $40 \%$ of the final culture contained B cells.

3.2. L-Selectin ${ }^{\text {low }}$ TDLNs Demonstrate Tumor-Specific Cytokine Secretion. The next experiment sought to measure the secretion of interferon- $\gamma$ (IFN- $\gamma$ ) by effector T cells, which is a major contributor to the antigen-specific therapeutic response in AIT. Secretion of the cytokine IFN $-\gamma$ by $4 \mathrm{~T} 1$ TDLN was examined under multiple conditions to assess tumor-specific reactivity in vitro (Figure 2). 4T1 TDLNs were fractionated to derive $\mathrm{L}$-selectin ${ }^{\text {low }}$ effector $\mathrm{T}$ cells which were then activated in culture for 5 days with anti-CD3 and IL-2. The activated $\mathrm{T}$ cells were then cultured for 24 hours under 4 different conditions: (1) TDLN alone as a negative control, (2) TDLN with immobilized anti-CD3 as a positive control, (3) TDLN with irradiated 4T1, and (4) TDLN with the irradiated renal cancer cell line Renca, which is MHC-compatible with 4T1 (MHC haplotype: $\left.\mathrm{H}-2 \mathrm{~K}^{\mathrm{d}}\right)$. 4T1 TDLN exhibited tumorspecific reactivity to $4 \mathrm{~T} 1$ cells compared to Renca cells as measured by secretion of IFN- $\gamma$. These data suggest that the culture-activated $\mathrm{T}$ cells obtained from lymph nodes draining 4T1 mammary cancers in this animal model are primed specifically against tumor antigens from the $4 \mathrm{~T} 1$ cell line.

3.3. Therapeutic Effectiveness of Adoptive Immunotherapy and the Role of the Recipient's Immune System. The next series of experiments sought to determine the therapeutic activity of TDLN in BALB/c mice in vivo. First, we evaluated the transfer of L-selectin ${ }^{\text {low }}$ cells into immunocompetent wildtype $\mathrm{BALB} / \mathrm{c}$ recipients bearing 3-day established tumors (Figure 3(a)). All 5 mice treated with control injections died of metastatic disease within 20 days. In contrast, all 5 mice treated with 4T1 TDLN demonstrated shrinkage of tumor with ultimate disappearance and cure. This finding shows that AIT using 4T1 L-selectin ${ }^{\text {low }}$ TDLN completely treats established 4T1 mammary cancers in this model.

In order to determine the contribution of the $\mathrm{CD} 4+$ and CD8+ T cell subtypes in the adoptively transferred cells to the overall therapeutic activity, the following experiment was performed. BALB/c mice bearing 3-day established tumors were treated with adoptive transfer of TDLN depleted of 


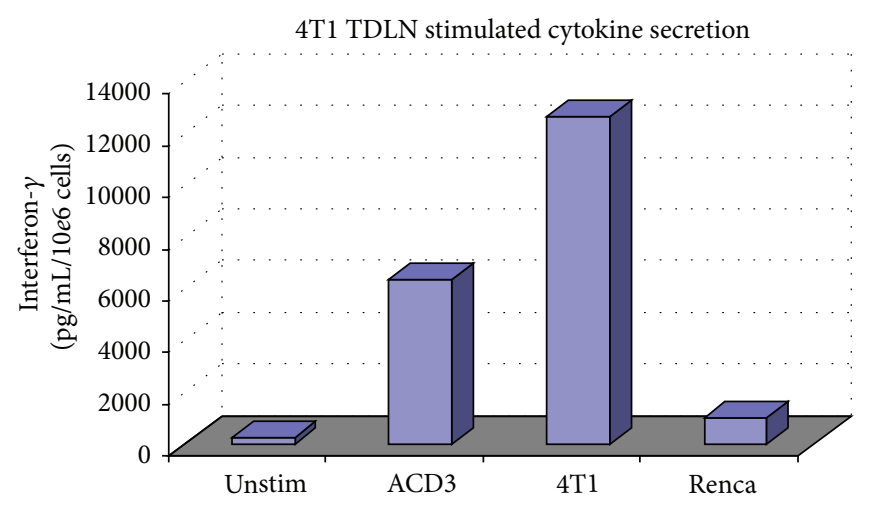

FIGURE 2: Activated TDLNs were cocultured alone, with immobilized anti-CD3, irradiated 4T1, or irradiated Renca tumor cells for 24 hours.

CD4+ or CD8+ cells (Figure 3(b)). Mice treated with T cells containing only CD8+ or CD4+ cells demonstrated tumor response and survival to 40 days, suggesting that both $\mathrm{T}$ cell subtypes play a role in antitumor activity. The majority of mice treated with only CD4+ T cells demonstrated cure, suggesting that the therapeutic efficacy appears to be primarily related to CD4+ T cells in this model system.

Finally, the contribution of the tumor bearing host's immune system on the therapeutic effects of adoptive $\mathrm{T}$ cell therapy was determined using recipient mice with specific immune deficiencies. 4T1 tumors were established subcutaneously in SCID mice, which lack T cells, B cells, and NK cells. All tumor-bearing SCID mice died of metastatic disease regardless of treatment with control injection or TDLN which was curative in immunocompetent wild-type BALB/c mice (Figure 3(c)). This finding suggests that some level of immune competence in the host is necessary for therapeutic efficacy of adoptively transferred TDLN. 4T1 tumors were also established subcutaneously in Rag2 deficient mice, which lack only $\mathrm{T}$ and $\mathrm{B}$ cells. Tumor-bearing Rag2 deficient mice that were administered control treatment died of metastatic disease, whereas those treated with TDLN were cured (Figure 3(d)). This finding suggests that NK cells or other components of the innate immune system within the tumor-bearing host are necessary for anti-tumor efficacy of transferred TDLN in this model.

\section{Discussion}

In this study, we demonstrated that AIT using cultureactivated L-selectin $^{\text {low }} \mathrm{T}$ cells derived from 4T1 TDLN cause tumor regression in a syngeneic murine model of mammary cancer. Culture-activated 4T1 TDLN cells demonstrated tumor-specific $\mathrm{T}$ cell reactivity evidenced by secretion IFN- $\gamma$ in response to $4 \mathrm{~T} 1$, but not Renca tumor cells, in vitro. Both CD4 and CD8 $\mathrm{T}$ cells were necessary for maximal antitumor effect, but CD4 cells demonstrated more therapeutic activity than CD8 cells. Using mice deficient in components of the immune system, we found that NK cells and/or other components of the innate immune system in the tumor-bearing host are necessary for antitumor effect of the transferred TDLN cells in this model.

Modulating the immune system in order to treat cancer is a treatment approach which has been expanding in clinical use recently. Adoptive immunotherapy with the activation of immune cells ex vivo followed by cell transfer into the tumorbearing host has been a method used for over 20 years, with moderate clinical success [28]. Many different strategies had been used both in the clinical and research settings. This includes infusion of tumor-infiltrating lymphocytes (TILs), lymphokine-activated killer cells (LAKs), vaccine-primed lymphocytes, T cells genetically engineered to express tumorspecific antigen receptors, and T cells with chimeric antigen receptors (CARs). T cell therapy has been combined with infusion of the $\mathrm{T}$ cell growth factor IL-2, as well as nonmyeloablative leukoreductive therapy using chemotherapy with or without total body radiation. The combined therapy using nonmyeloablative chemotherapy, $\mathrm{T}$ cell infusion, and systemic IL-2 has demonstrated 20\% complete response rate and $70 \%$ overall response rate in melanoma patients [29].

Isolating $\mathrm{T}$ cells from tumor-draining lymph nodes provides another source for cellular immunotherapy. Lymph nodes draining a growing tumor contain tumor-sensitized pre-effector T cells. Ex vivo activation and expansion with anti-CD3 and IL-2 differentiate these preeffector cells into effector T cells $[12,13]$. Numerous animal studies have shown the therapeutic efficacy of TDLN immunotherapy, and in vitro studies have shown tumors cytotoxicity of human TDLN cells to human melanoma cells $[5,8,12,13,17,18,20,21]$.

Down regulation of L-selectin on T cells is an early event in the response of antigenic stimulation. L-selectin ${ }^{\text {low }} \mathrm{T}$ cells comprised $30 \%$ of our TDLN population, which is consistent with other reports [24]. Adoptive transfer of isolated Lselectin $^{\text {low }} \mathrm{T}$ cells has demonstrated therapeutic antitumor efficacy in a sarcoma animal model, while isolated infusion of L-selectin $^{\text {high }} \mathrm{T}$ cells was ineffective [24]. In addition, interferon- $\gamma$ production in response to tumor exposure is significantly higher in L-selectin ${ }^{\text {low }}$ versus $\mathrm{L}$ selectin ${ }^{\text {high }} \mathrm{T}$ cells, suggesting this population contains more tumor reactive $\mathrm{T}$ cells [21]. Furthermore, infusion of L-selectin ${ }^{\text {high }}$ cells from TDLN have been shown to block effector responses in adoptive 

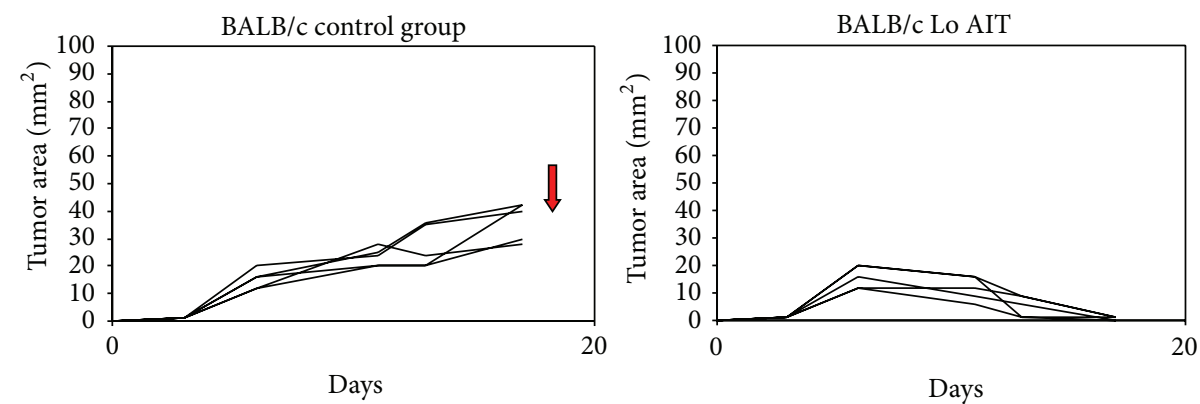

(a)
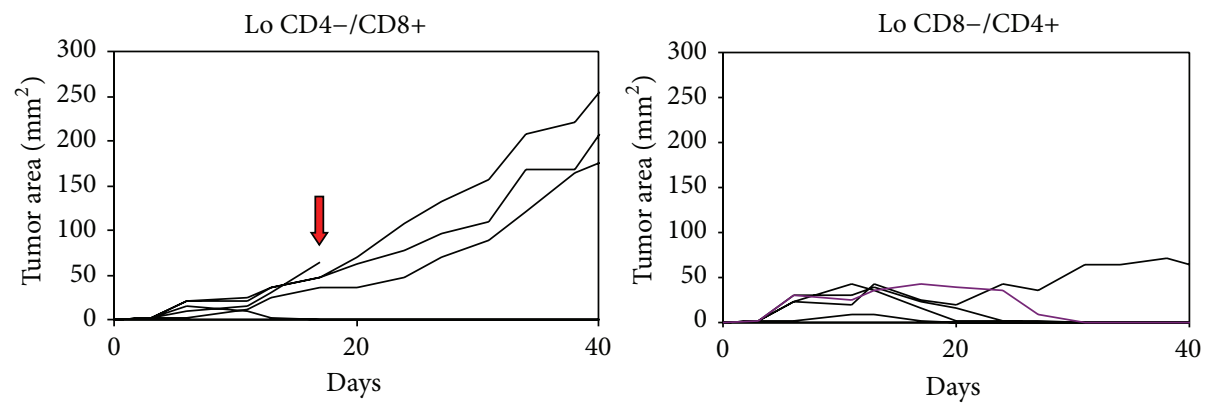

(b)
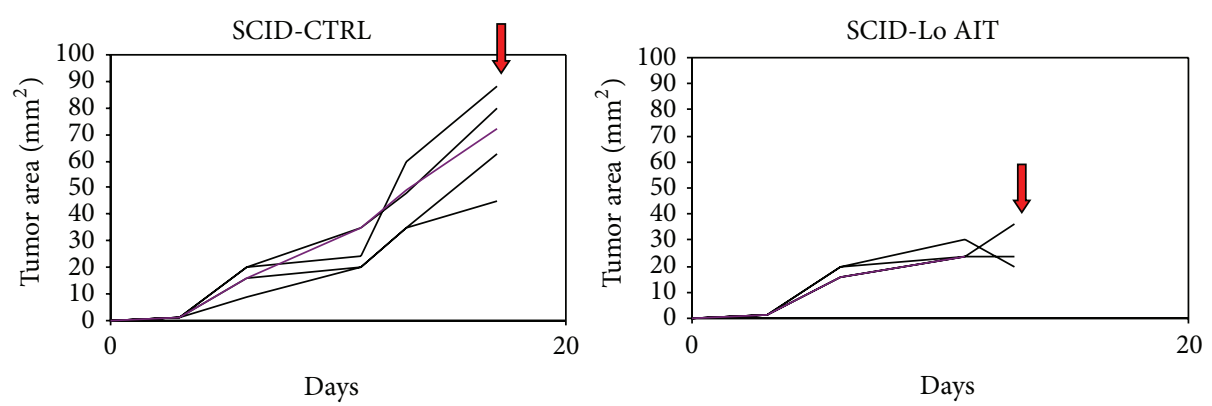

(c)
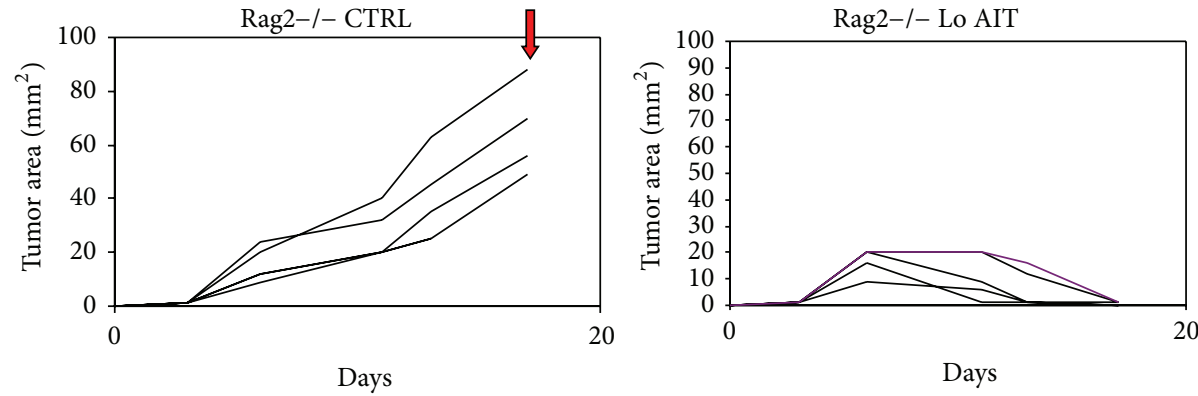

Mice died of metastatic disease

(d)

FIgURE 3: (a) 4T1 TDLNs transferred into BALB/c mice. BALB/c mice bearing 3-day established 4T1 subcutaneous tumors treated with 4T1 TDLNs (Lo AIT) were cured of tumor while those treated with HBSS (control) died of metastatic disease. Each line represents one mouse $(n=5)$. (b) CD4/CD8 depleted TDLNs into BALB/c mice. BALB/c mice with $4 \mathrm{~T} 1$ subcutaneous tumors were treated with $4 \mathrm{~T} 1 \mathrm{TDLNs}$ depleted of CD4 or CD8 cells. Therapeutic efficacy of transferred TDLN appears to be primarily related to intact CD4. Each line represents one mouse $(n=5)$. (c) 4T1 TDLNs transferred into SCID mice. SCID mice bearing 3-day established $4 \mathrm{~T} 1$ subcutaneous tumors treated with 4T1 TDLNs and control mice all died, suggesting the need for some immune competence in the tumor-bearing mice for tumorigenicity of transferred TDLNs. Each line represents one mouse $(n=5)$. (d) 4T1 TDLNs transferred into Rag2-/- mice. Rag2-/- mice bearing 3-day established 4T1 subcutaneous tumors were treated with HBSS (CTRL, $n=4$ ) or 4T1 TDLNs (Lo AIT, $n=5$ ). Results suggest that NK cells within the tumor-bearing host are necessary for therapeutic activity of transferred TDLN. Each line represents one mouse. 
immunotherapy protocols using TDLN in an animal model [26]. The use of L-selectin ${ }^{\text {low }} \mathrm{T}$ cells is an attractive methodology for immunotherapy protocols as it allows for isolation of a population of highly reactive antitumor effector cells which can then be expanded tremendously. Although adoptive immunotherapy using L-selectin ${ }^{\text {low }}$ cells from TDLN in other animal models has used sublethal radiation for conditioning, the therapy described in our experimental model did not use radiation or IL-2 as an adjunct. This has potential relevance for clinical application of this therapy administered in the absence of conditioning with radiation or IL-2, which both have their toxicities.

Although both adoptively transferred CD 4 and CD8 cells were required for tumor regression, $\mathrm{CD} 4$ cells were more effective. CD8+ cytotoxic T cells are exclusively used in many adoptive immunotherapy models as these are known to have effector function after activation. In a sarcoma model using anti-CD3 activated TDLN, CD8 cells caused tumor regression while $\mathrm{CD} 4$ cells did not result in tumor regression but instead provided a helper function to CD8 cells that could be replaced with exogenous IL-2 [13]. However, in a similar sarcoma model using TDLN which were anti-CD3/antiCD28 activated, CD4 cells were more potent effector cells than CD8 cells [15]. Similarly, another report showed that L-selectin ${ }^{\text {low }} \mathrm{CD} 4$ cells caused tumor regression [23]. It has also been reported that progressive tumor growth in syngeneic mice leads to independent sensitization of both TDLN L-selectin ${ }^{\text {low }} \mathrm{CD} 4$ and CD8 cells, with CD4 cells being more effective against 3-day established intracranial and pulmonary tumors and CD8 cells more effective against 10-day established tumors [25]. In the current study, tumor regression was most effective with both CD4 and CD8 cells. CD4 cells demonstrate direct cytotoxicity and likely provide a supportive role by secretion of cytokines to enhance CD8 cells cytotoxicity. Similar to previous reports, the antitumor activity did not require exogenous IL-2.

Though not investigated in the current study, it is possible that adoptively transferred $\mathrm{B}$ cells played a role in mediating tumor regression. B cells predominantly perform antigenpresentation and antibody production. Although $\mathrm{T}$ cells are the predominant effector cells, B cells can also function as effector cells. In a mouse model of pulmonary metastases, activated TDLN B cells mediated significant tumor regression. This response was enhanced by the addition of activated TDLN T cells [30]. Activated B cells in adoptive immunotherapy of solid tumors have demonstrated regression of sarcoma, melanoma, and breast cancer [30, 31]. The mechanism for B cell tumor activity is unknown, but the B cells may support the antitumor activity of the activated T cells in culture. In addition, $B$ cells' role as antigen-presenting cells may enhance the host's $\mathrm{T}$ cell response. The adoptive transfer of activated $\mathrm{B}$ cells specific for $4 \mathrm{~T} 1$ into hosts bearing $4 \mathrm{~T} 1$ tumors resulted in the induction of systemic T cell immunity to 4T1 [31].

NK cells are effector lymphocytes of the innate immune system which were found to be an integral component within the host for tumor response in the studied model system. NK cells do not require antigen recognition and are able to lyse tumor cells without prior stimulation [32-34]. They recognize target cells through activating receptors on the cell surface. Mechanisms involved in tumor cytotoxicity include perforin/granzyme mediated cytotoxicity, death receptor mediated apoptosis, and IFN- $\gamma$ secretion [35]. NK cells play a role in tumor immunosurveillance as evidenced by the fact that mice deficient in NK cells are more susceptible to methylcholanthrene-induced sarcomas [36]. In addition, NK cells mitigate the growth of lymphomas in mice lacking perforin and $\beta 2$ microglobulin [37]. Furthermore, NK cells prevent pulmonary and peritoneal metastases and peritoneal dissemination in murine models $[38,39]$. Other experimental models have demonstrated the cooperation of the innate and adaptive immune systems. For example, in a murine model of intraperitoneal tumors of mesenchymal origin, complete tumor rejection was dependent on both $\mathrm{T}$ cells and NK cells [40]. Similarly, in a murine model of subcutaneous and lung tumors, treatment of subcutaneous tumors using photodynamic therapy led to a CD8 and NK dependent inhibition of growth of untreated lung tumors [30]. In treatment models using dendritic cell-based adoptive immunotherapy, the interaction of NK cells with dendritic cells and $T$ cells has been shown to be important for antitumor responses [38]. In the model used in the current study, there is evidence of cooperation of the innate and adaptive immune systems. NK cells may have a direct cytotoxic effect upon exposure to the tumor. Alternatively, cytokine release from CD4 and/or CD8 cells may trigger an NK cell response.

In conclusion, the present study demonstrated that (1) adoptive transfer of culture-activated 4T1 TDLN cells into immunocompetent syngeneic tumor-bearing hosts results in tumor regression, (2) culture-activated 4T1 TDLN cells secrete interferon-gamma in response to $4 \mathrm{~T} 1$ but not Renca tumor cells in vitro, demonstrating the presence of tumorspecific T cell reactivity, (3) adoptive transfer of L-selectin ${ }^{\text {low }}$ subpopulations into immunocompetent tumor-bearing hosts suggests that CD4 cells within the culture-activated TDLN mediate a significant proportion of the antitumor effect, and (4) adoptive transfer of culture-activated 4T1 TDLN into SCID and Rag2 deficient mice suggests that NK cells within the tumor-bearing host are critical to the observed antitumor effect. These results demonstrate the interaction between cellular components of both the adaptive and innate immune systems in this model of AIT using TDLNs. Strategies to enhance the interaction between adoptively transferred $\mathrm{T}$ cells and resident NK cells or innate immunity may result in improved antitumor therapeutic efficacy.

\section{Conflict of Interests}

The authors declare that there is no conflict of interests regarding the publication of this paper.

\section{References}

[1] A. E. Chang, Q. Li, G. Jiang, D. M. Sayre, T. M. Braun, and B. G. Redman, "Phase II trial of autologous tumor vaccination, antiCD3-activated vaccine-primed lymphocytes, and interleukin-2 in stage IV renal cell cancer," Journal of Clinical Oncology, vol. 21, no. 5, pp. 884-890, 2003. 
[2] S. A. Rosenberg, P. Spiess, and R. Lafreniere, "A new approach to the adoptive immunotherapy of cancer with tumor-infiltrating lymphocytes," Science, vol. 233, no. 4770, pp. 1318-1321, 1986.

[3] Q. Li, A. Carr, F. Ito, S. Teitz-Tennenbaum, and A. E. Chang, "Polarization effects of 4-1BB during CD28 costimulation in generating tumor-reactive T cells for cancer immunotherapy," Cancer Research, vol. 63, no. 10, pp. 2546-2552, 2003.

[4] Q. Li, B. Yu, A. C. Grover, X. Zeng, and A. E. Chang, "Therapeutic effects of tumor reactive CD4+ cells generated from tumor-primed lymph nodes using anti-CD3/anti-CD28 monoclonal antibodies," Journal of Immunotherapy, vol. 25, no. 4, pp. 304-313, 2002.

[5] T. Iuchi, S. Teitz-Tennenbaum, J. Huang et al., "Interleukin-21 augments the efficacy of T-cell therapy by eliciting concurrent cellular and humoral responses," Cancer Research, vol. 68, no. 11, pp. 4431-4441, 2008.

[6] Q. Li, S. A. Furman, C. R. Bradford, and A. E. Chang, "Expanded tumor-reactive CD4+ T-cell responses to human cancers induced by secondary anti-CD3/anti-CD28 activation," Clinical Cancer Research, vol. 5, no. 2, pp. 461-469, 1999.

[7] R. Kiessling, E. Klein, and H. Wigzell, "Natural' killer cells in the mouse. I. Cytotoxic cells with specificity for mouse Moloney leukemia cells. Specificity and distribution according to genotype," European Journal of Immunology, vol. 5, no. 2, pp. 112-117, 1975.

[8] S. A. Rosenberg, "Cell transfer immunotherapy for metastatic solid cancer-what clinicians need to know," Nature Reviews Clinical Oncology, vol. 8, no. 10, pp. 577-585, 2011.

[9] S. A. Rosenberg and M. E. Dudley, "Adoptive cell therapy for the treatment of patients with metastatic melanoma," Current Opinion in Immunology, vol. 21, no. 2, pp. 233-240, 2009.

[10] S. A. Rosenberg, M. T. Lotze, L. M. Muul et al., "A progress report on the treatment of 157 patients with advanced cancer using lymphokine-activated killer cells and interleukin-2 or high-dose interleukin-2 alone," The New England Journal of Medicine, vol. 316, no. 15, pp. 889-897, 1987.

[11] S. Shu, R. A. Krinock, T. Matsumura et al., "Stimulation of tumor-draining lymph node cells with superantigenic staphylococcal toxins leads to the generation of tumor-specific effector $\mathrm{T}$ cells," The Journal of Immunology, vol. 152, no. 3, pp. 1277-1288, 1994.

[12] A. E. Chang, B. G. Redman, J. R. Whitfield et al., "A Phase I trial of tumor lysate-pulsed dendritic cells in the treatment of advanced cancer," Clinical Cancer Research, vol. 8, no. 4, pp. 1021-1032, 2002.

[13] A. E. Chang, H. Yoshizawa, K. Sakai, M. J. Cameron, V. K. Sondak, and S. Shu, "Clinical observations on adoptive immunotherapy with vaccine-primed T-lymphocytes secondarily sensitized to tumor in vitro," Cancer Research, vol. 53, no. 5, pp. 1043-1050, 1993.

[14] D. L. Porter, B. L. Levine, M. Kalos, A. Bagg, and C. H. June, "Chimeric antigen receptor-modified $\mathrm{T}$ cells in chronic lymphoid leukemia," The New England Journal of Medicine, vol. 365, no. 8, pp. 725-733, 2011.

[15] A. Aruga, E. Aruga, M. J. Cameron, and A. E. Chang, "Different cytokine profiles released by $\mathrm{CD}^{+}$and $\mathrm{CD}^{+}$tumor-draining lymph node cells involved in mediating tumor regression," Journal of Leukocyte Biology, vol. 61, no. 4, pp. 507-516, 1997.

[16] H. Yoshizawa, A. E. Chang, and S. Y. Shu, "Cellular interactions in effector cell generation and tumor regression mediated by anti-CD3/interleukin 2-activated tumor-draining lymph node cells," Cancer Research, vol. 52, no. 5, pp. 1129-1136, 1992.
[17] K. R. Stephenson, D. Perry-Lalley, K. D. Griffith, S. Shu, and A. E. Chang, "Development of antitumor reactivity in regional draining lymph nodes from tumor-immunized and tumorbearing murine hosts," Surgery, vol. 105, no. 4, pp. 523-528, 1989.

[18] H. Tanaka, J. Tanaka, J. Kjaergaard, and S. Shu, "Depletion of CD4+CD25+ regulatory cells augments the generation of specific immune T cells in tumor-draining lymph nodes," Journal of Immunotherapy, vol. 25, no. 3, pp. 207-217, 2002.

[19] H. Yoshizawa, K. Sakai, A. E. Chang, and S. Shu, "Activation by anti-CD3 of tumor-draining lymph node cells for specific adoptive immunotherapy," Cellular Immunology, vol. 134, no. 2, pp. 473-479, 1991.

[20] A. Visioni, M. Zhang, H. Graor, and J. Kim, "Expansion of melanoma-specific $\mathrm{T}$ cells from lymph nodes of patients in stage III: implications for adoptive immunotherapy in treating cancer," Surgery, vol. 152, no. 4, pp. 557-566, 2012.

[21] L.-X. Wang, B.-G. Chen, and G. E. Plautz, "Adoptive immunotherapy of advanced tumors with CD62 Lselectin $^{\text {low }}$ tumor-sensitized $\mathrm{T}$ lymphocytes following ex vivo hyperexpansion," The Journal of Immunology, vol. 169, no. 6, pp. 3314-3320, 2002.

[22] L. Peng, J. Kjaergäard, G. E. Plautz et al., "Tumor-induced L-selectinhigh suppressor $\mathrm{T}$ cells mediate potent effector $\mathrm{T}$ cell blockade and cause failure of otherwise curative adoptive immunotherapy," Journal of Immunology, vol. 169, no. 9, pp. 4811-4821, 2002.

[23] C. A. Klebanoff, H. T. Khong, P. A. Antony, D. C. Palmer, and N. P. Restifo, "Sinks, suppressors and antigen presenters: how lymphodepletion enhances $\mathrm{T}$ cell-mediated tumor immunotherapy," Trends in Immunology, vol. 26, no. 2, pp. 111117, 2005.

[24] S. A. Rosenberg, N. P. Restifo, J. C. Yang, R. A. Morgan, and M. E. Dudley, "Adoptive cell transfer: a clinical path to effective cancer immunotherapy," Nature Reviews Cancer, vol. 8, no. 4, pp. 299-308, 2008.

[25] H. Kagamu and S. Shu, "Purification of L-selectin(low) cells promotes the generation of highly potent CD4 antitumor effector T lymphocytes," The Journal of Immunology, vol. 160, no. 7, pp. 3444-3452, 1998.

[26] J. Yu, R. Tian, B. Xiu et al., "Antitumor activity of $t$ cells generated from lymph nodes draining the sea-expressing murine B16 melanoma and secondarily activated with dendritic cells," International Journal of Biological Sciences, vol. 5, no. 2, pp. 135146, 2009.

[27] S. A. Rosenberg, J. C. Yang, R. M. Sherry et al., "Durable complete responses in heavily pretreated patients with metastatic melanoma using T-cell transfer immunotherapy," Clinical Cancer Research, vol. 17, no. 13, pp. 4550-4557, 2011.

[28] J. R. Ortaldo, R. K. Oldham, G. C. Cannon, and R. B. Herberman, "Specificity of natural cytotoxic reactivity of normal human lymphocytes against a myeloid leukemia cell line," Journal of the National Cancer Institute, vol. 59, no. 1, pp. 77-82, 1977.

[29] C. Riccardi, A. Santoni, T. Barlozzari, P. Puccetti, and R. B. Herberman, "In vivo natural reactivity of mice against tumor cells," International Journal of Cancer, vol. 25, no. 4, pp. 475486, 1980.

[30] Q. Li, S. Teitz-Tennenbaum, E. J. Donald, M. Li, and A. E. Chang, "In vivo sensitized and in vitro activated B cells mediate tumor regression in cancer adoptive immunotherapy," The Journal of Immunology, vol. 183, no. 5, pp. 3195-3203, 2009. 
[31] Q. Li, X. Lao, Q. Pan et al., "Adoptive transfer of tumor reactive B cells confers host T-cell immunity and tumor regression," Clinical Cancer Research, vol. 17, no. 15, pp. 4987-4995, 2011.

[32] M. J. Smyth, N. Y. Crowe, and D. I. Godfrey, "NK cells and NKT cells collaborate in host protection from methylcholanthreneinduced fibrosarcoma," International Immunology, vol. 13, no. 4, pp. 459-463, 2001.

[33] S. E. A. Street, Y. Hayakawa, Y. Zhan et al., "Innate immune surveillance of spontaneous B cell lymphomas by natural killer cells and $\gamma \delta$ T cells," The Journal of Experimental Medicine, vol. 199, no. 6, pp. 879-884, 2004.

[34] A. Ksienzyk, B. Neumann, R. Nandakumar et al., "IRF-1 expression is essential for natural killer cells to suppress metastasis," Cancer Research, vol. 71, no. 20, pp. 6410-6418, 2011.

[35] S. Zhou, S. Kawakami, Y. Higuchi, F. Yamashita, and M. Hashida, "The involvement of NK cell activation following intranasal administration of CpG DNA lipoplex in the prevention of pulmonary metastasis and peritoneal dissemination in mice," Clinical \& Experimental Metastasis, vol. 29, no. 1, pp. 6370, 2012.

[36] A. Arina, O. Murillo, S. Hervás-Stubbs et al., “The combined actions of $\mathrm{NK}$ and $\mathrm{T}$ lymphocytes are necessary to reject an EGFP+ mesenchymal tumor through mechanisms dependent on NKG2D and IFN $\gamma$," International Journal of Cancer, vol. 121, no. 6, pp. 1282-1295, 2007.

[37] E. Kabingu, L. Vaughan, B. Owczarczak, K. D. Ramsey, and S. O. Gollnick, "CD8 ${ }^{+} \mathrm{T}$ cell-mediated control of distant tumours following local photodynamic therapy is independent of $\mathrm{CD} 4^{+}$ T cells and dependent on natural killer cells," British Journal of Cancer, vol. 96, no. 12, pp. 1839-1848, 2007.

[38] E. Lion, E. L. J. M. Smits, Z. N. Berneman, and V. F. I. Van Tendeloo, "NK Cells: key to success of DC-based cancer vaccines?” The Oncologist, vol. 17, no. 10, pp. 1256-1270, 2012.

[39] T. Kawaoka, M. Oka, M. Takashima et al., "Adoptive immunotherapy for pancreatic cancer: cytotoxic $\mathrm{T}$ lymphocytes stimulated by the MUC1 -expressing human pancreatic cancer cell line YPK-1," Oncology Reports, vol. 20, no. 1, pp. 155-163, 2008.

[40] J.-P. Machiels, N. van Baren, and M. Marchand, "Peptide-based cancer vaccines," Seminars in Oncology, vol. 29, no. 5, pp. 494$502,2002$. 


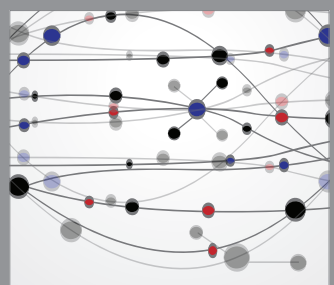

The Scientific World Journal
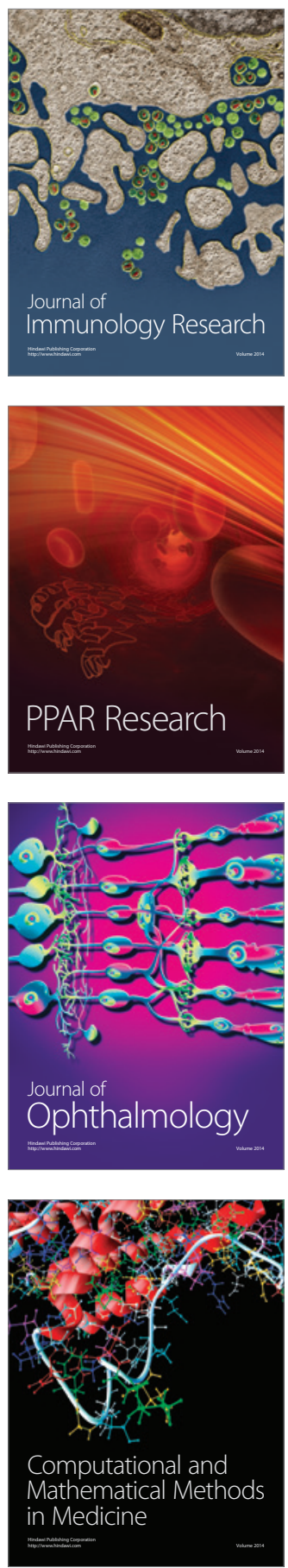

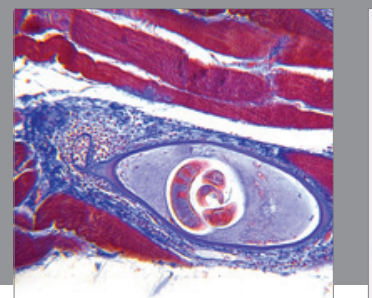

Gastroenterology

Research and Practice
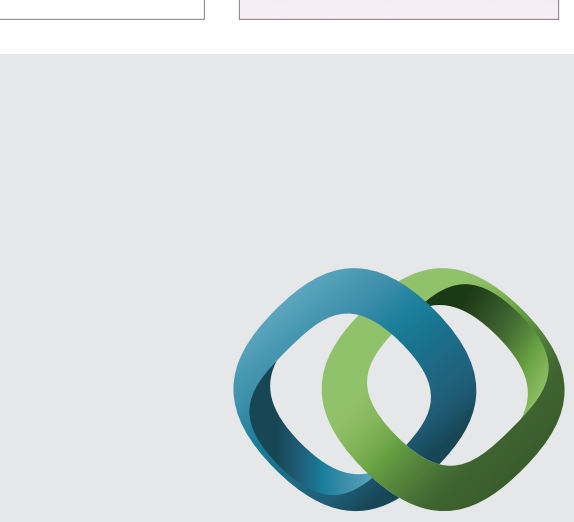

\section{Hindawi}

Submit your manuscripts at

http://www.hindawi.com
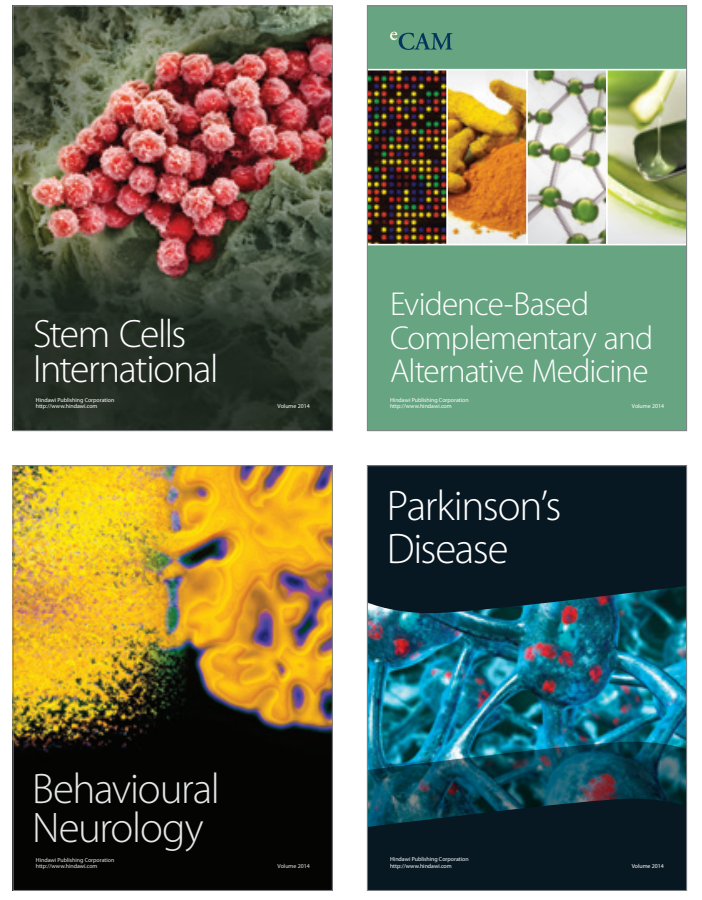
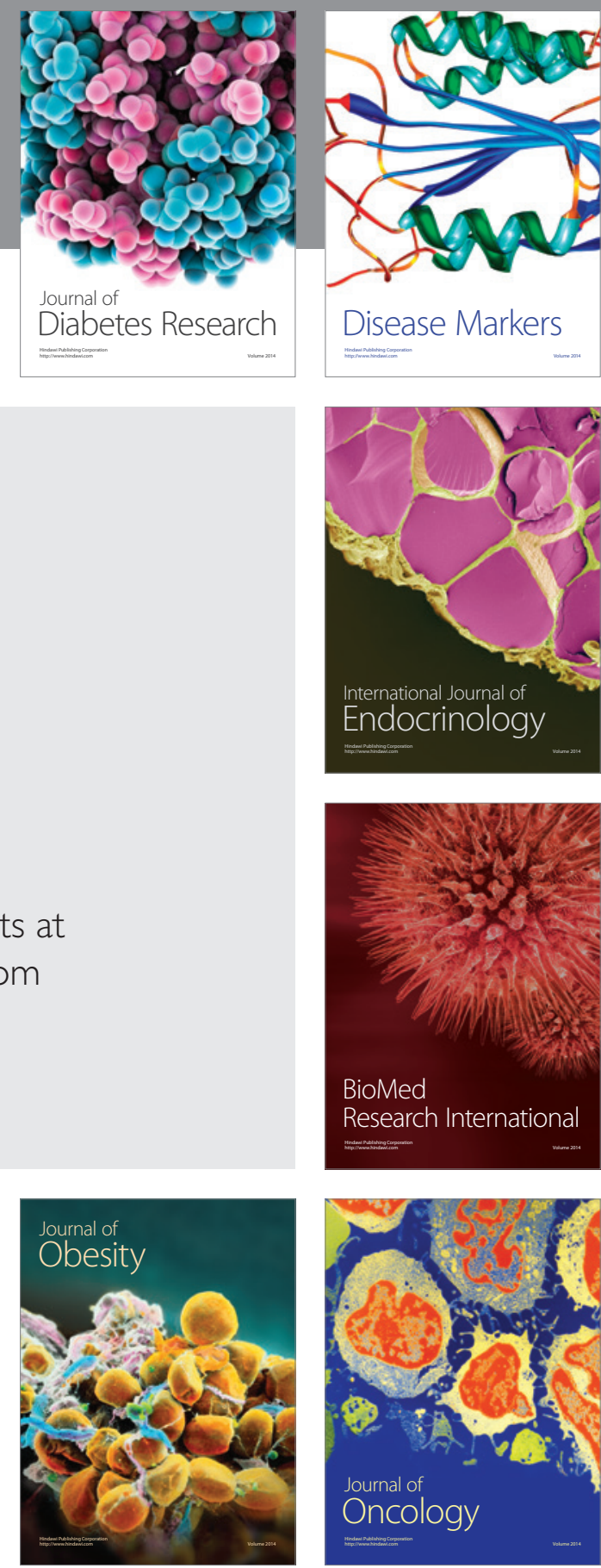

Disease Markers
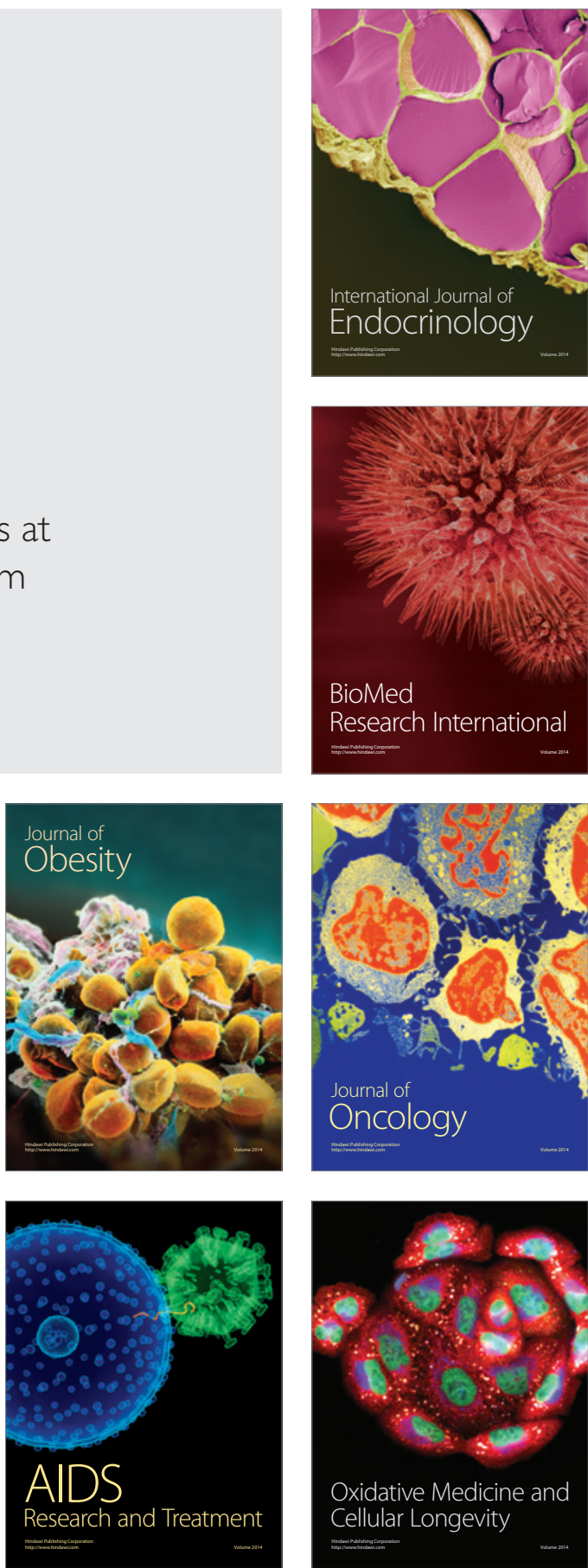